\title{
Using the ECMWF OpenIFS model and state-of-the-art training techniques in meteorological education
}

\author{
Gabriella Szépszó $^{1,2}$, Victoria Sinclair ${ }^{3}$, and Glenn Carver $^{1}$ \\ ${ }^{1}$ European Centre for Medium-Range Weather Forecasts, Reading, UK \\ ${ }^{2}$ Hungarian Meteorological Service, Budapest, Hungary \\ ${ }^{3}$ University of Helsinki, Helsinki, Finland \\ Correspondence: Gabriella Szépszó (szepszo.g@met.hu)
}

Received: 24 January 2019 - Accepted: 7 March 2019 - Published: 8 April 2019

\begin{abstract}
The OpenIFS programme of the European Centre for Medium-Range Weather Forecasts (ECMWF) maintains a version of the ECMWF forecast model (IFS; Integrated Forecasting System) for use in education and research at universities, national meteorological services and other institutes. The OpenIFS model can be run on high-performance computing systems, desktop or laptop computers to produce weather forecasts in a similar way to the operational forecasts at ECMWF. Application of OpenIFS as a training tool is wide ranging. At several universities, masters students are taught modelling aspects via sensitivity studies, such as numerical stability, impact of spatial resolution and physical parameterisation settings on the forecast quality. The OpenIFS single column model is used to study a subset of physical processes in the atmosphere. Participants of the OpenIFS user workshops are trained through selected weather events on interpretation of different forecasts, for example ensemble forecasts, probabilistic information, seasonal forecasts. The OpenIFS user meetings and training events demonstrate advanced and easy-to-use graphical tools and training technologies. Metview is developed to analyse, visualise and evaluate the forecast outputs. OpenIFS and Metview "virtual machines" relieve the tutors from the difficulties often found in installing this software on the local computing environment. They provide data, applications and documents in a package tested in-house and deployed easily to another site. A further step on virtualisation is utilising cloud servers, ensuring the computational resources demanded by model runs are available in the cloud space. This paper shows the education activity in the OpenIFS programme with some examples.
\end{abstract}

\section{Introduction}

The European Centre for Medium-Range Weather Forecasts (ECMWF) is both a research institute and an operational service, producing and disseminating global numerical weather predictions and other data to its Member and Co-operating States as well as to the broader community. The comprehensive Earth-system model developed at ECMWF forms the basis for all data assimilation and forecasting activities through one computer software system called the Integrated Forecasting System (IFS).

Developments of ECMWF are based on European scientific and technical co-operation in meteorology and in highperformance computing. To strengthen external collaborations, ECMWF launched the OpenIFS initiative in 2011. The mission of the OpenIFS project is to increase the expertise on IFS at universities and other research institutions and to bring new scientific collaborations on research topics of interest. To support this, ECMWF develops and maintains an easy-to-use version of its operational global IFS model.

A software licensing agreement with ECMWF is required to use the OpenIFS model. License agreements are free and limited to non-commercial use for research or educational organisations. At the start of 2019 there are more than 60 licensed institutes mainly from Europe, but also from Japan, China, South Korea, India, Brazil, Peru, Morocco and the United States. OpenIFS is currently based on IFS cycle 40r1 (Bauer and Richardson, 2014) which was operational in 2013-2014. OpenIFS has the same forecast capability as 


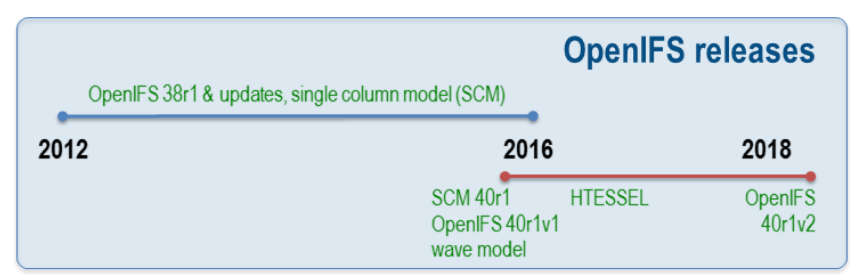

Figure 1. Evolution of OpenIFS between 2012 and 2018. The "38r1" and "40r1" OpenIFS cycle numbers are taken from the corresponding IFS cycle on which the OpenIFS release is based ("40r1" refers to the IFS model release 1 of cycle 40). The "v1" and "v2" version numbers are unique to OpenIFS and used to indicate updates to OpenIFS only. HTESSEL (Balsamo et al., 2009) is the version of the Tiled ECMWF Scheme for Surface Exchanges over Land (TESSEL) and used operationally in IFS for describing the evolution of soil, vegetation and snow over the continents at diverse spatial resolutions.

IFS but it excludes the observation processing and the data assimilation.

The OpenIFS model is extensively used in meteorological education. Besides the intention to provide training on meteorological modelling and computing, the involved institutes aim to develop and improve work-relevant skills of masters and PhD students, bridging the gap between their studies and real research using a complex, state-of-the-art numerical weather prediction model with a variety of approaches. At the École Nationale de la Météorologie (ENM) of Météo-France, universities of Ghent and Oxford, a meteorological story has been built up around a selected case study to demonstrate some key features of the meteorological modelling like necessity of the ensemble approach. At the Hungarian Meteorological Service, universities of Helsinki, Reading and Stockholm, different model settings are tested on a given forecast case to teach some aspects of the numerical methods and the physical parameterisations. At the universities of Innsbruck and Perugia, the focus is on vertical column processes, the students investigate "what if" questions with the single column model (originally developed by Martin Köhler and João Teixeira in 2002) available since 2016 (Váňa and Ahlgrimm, 2018; Fig. 1). ECMWF itself also delivers courses based on OpenIFS (IFS) combined with further ECMWF software and modern training techniques like e-learning, virtual machines and cloud technology. In this paper, we show some examples for training and teaching activities based on OpenIFS.

\section{OpenIFS user workshops}

OpenIFS user workshops are organised annually or biannually jointly by a university or research institute and the OpenIFS team from ECMWF. The meetings between 2013 and 2017 were held at the universities of Helsinki, Stockholm, ECMWF (organised with the University of Oxford) and the International Centre for Theoretical Physics in Trieste, respectively. The aims of the meetings are to promote OpenIFS to the local and wider community and bring together scientists, current and prospective OpenIFS users to discuss the workshop theme. The event is devoted to a different scientific topic each year, discussed in keynote talks and explored via case studies in the practical sessions. For example, predictability issues and the importance of ensemble predictions were demonstrated with Hurricane Sandy (Carver et al., 2013); convection parameterisation was investigated with case studies of tornado formation in the USA and convection over Africa (Hannachi and Carver, 2014); seasonal forecasts and teleconnections were studied via the 2015-2016 El Niño (Carver, 2017).

The participants have the possibility to run forecasts with OpenIFS or they analyse the model outputs produced at ECMWF prior to the training course (see Fig. 2 for the 2015-2016 seasonal predictions). The OpenIFS single column model has occasionally been used in the meetings to experiment with modifying physical parameterisations. To visualise and evaluate the results, the analysis and visualisation software Metview is applied. This is developed in cooperation between ECMWF and the Brazilian National Institute for Space Research (Russell et al., 2014). It features an iconbased user interface for interactive work and a macro scripting language for batch processing. For the workshops, custom easy-to-use Metview icons and macros are prepared for each experiment with detailed tutorials on the exercises for the participants to follow.

A key feature of some meetings is the use of Linux virtual machines (VM). A virtual machine consists of a computer operating system and its applications running on top of another operating system. This is an effective way of delivering remote workshop practicals involving real models, data and analysis tools. The OpenIFS virtual machines contain a pre-installed version of Metview, pre-compiled OpenIFS and single column model executables as well as all the results of the different OpenIFS simulations run at ECMWF prior to the meeting. It is deployed via FTP or on a USB stick and the participants can use them by installing a "virtual machine player" on the classroom computers.

\section{Training at Météo-France ENM}

The practical sessions of the OpenIFS workshops inspired the masters courses at several universities for example in Reading (Plant and Gray, 2017), Oxford as well as at the École Nationale de la Météorologie in France. The OpenIFS team returned to Météo-France for the third consecutive year in 2018 to run a training course for engineers of the school. It forms a part of the teaching programme at ENM and is now an established collaboration with OpenIFS outreach activities (Carver et al., 2016). 
(a) Sea surface temperature difference; December 2015

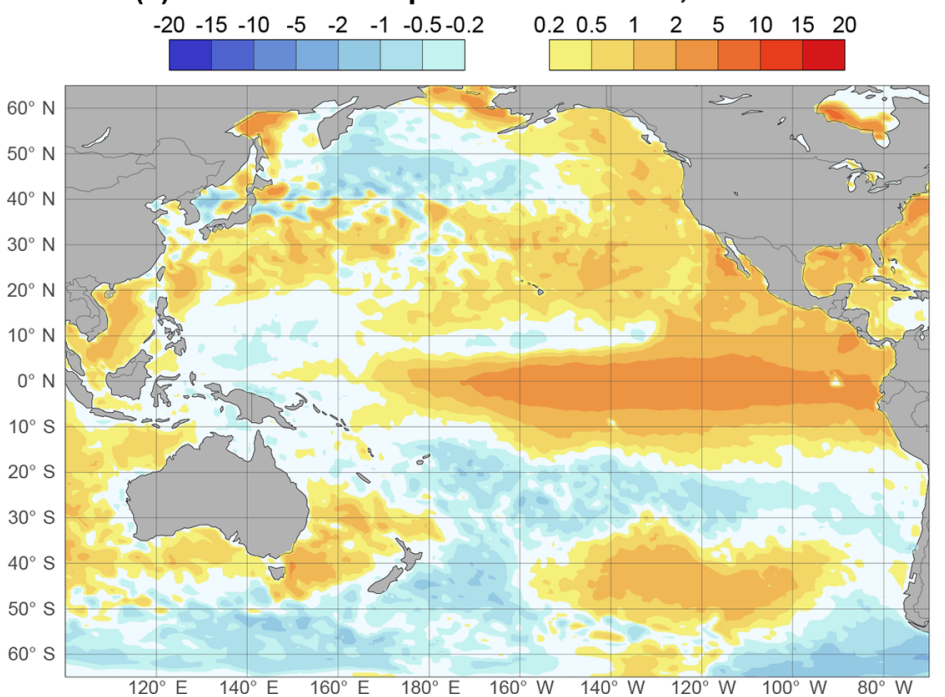

(b) 2 m temperature anomaly; January 2016

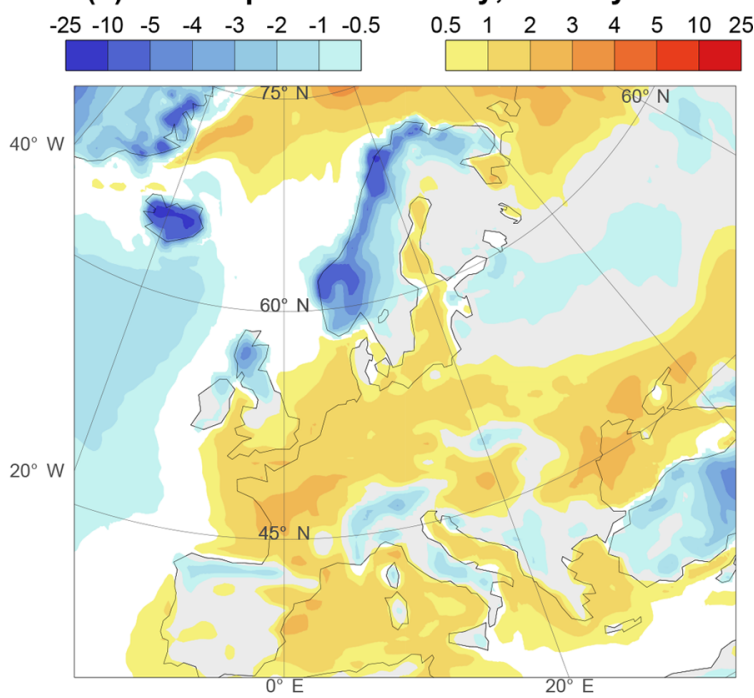

Figure 2. (a) Difference between the observed and the climatological sea surface temperature (SST; in ${ }^{\circ} \mathrm{C}$ ). The observed SST represents the ERA-Interim re-analysis and the climatological SST represents 20-year mean of the ERA-Interim re-analysis. (b) $2 \mathrm{~m}$ temperature anomaly $\left({ }^{\circ} \mathrm{C}\right)$ of the ensemble mean of a 10-member OpenIFS seasonal forecast 2015 using observed SST values with respect to ERAInterim climatological mean from 1981 to 2010. The forecast was initialised on 1 November 2015 and the ten ensemble members were generated using the stochastic scheme for the physics tendencies (Buizza et al., 1999; Leutbecher et al., 2017) and the stochastic kinetic energy backscatter scheme (Shutts, 2005) in the model dynamics. The figures represent monthly mean values (a) for December 2015 over the Pacific region and (b) for January 2016 over Europe. Although El Niño is a coupled ocean-atmosphere phenomenon centred over the tropical Pacific the key effect of which is the warming of the equatorial Pacific Ocean, it can have climate impacts also in remote parts of the globe. Fraedrich and Müller (1992) identified the colder January temperatures in northern Europe as one of such teleconnection patterns.

Fifteen ENM students took part in the course in 2018. They followed a prepared tutorial using ECMWF ensemble forecast data in a case study of hurricane Nadine during the HyMeX (Hydrological cycle in Mediterranean experiment; Drobinski et al., 2014) observational campaign in 2012. The course focused on part of Nadine's life cycle when the tropical cyclone interacted with the mid-latitude flow. The forecast uncertainty of this situation is naturally high, ideal for teaching as it demonstrates the need to establish ensemble forecasts. The exercises simulated a real forecast situation and put the students in the position of a duty forecaster supporting the HyMeX scientific director in decision making for flight planning based on probabilistic forecast information.

During the 3-day course, the students were presented with forecast information step-by-step, the same way a duty forecaster might receive the information. They explored the available analysis and the high-resolution operational forecast (HRES) first. The $16 \mathrm{~km}$ resolution IFS forecast predicted Nadine to move eastwards to the continent, at the same time a short-wave trough separated into a cut-off low and approached Nadine from the north (Fig. 3d). The orography of the Iberian Peninsula diverted the low-level flow over the Mediterranean Sea, resulting in strong, moist flow over southern France.

Afterwards the students looked at the differences between the HRES and control forecasts which both started from the same initial condition and differ only in the horizontal resolution. The $31 \mathrm{~km}$ resolution ensemble control forecast showed that Nadine made a loop back to the Atlantic and the interaction between the cyclone and the cut-off low was weak. The southwesterly wind from the Mediterranean caused large precipitation amounts over southern France. The investigations were extended with the 50-member operational ensemble forecast of ECMWF which has the same resolution as the control forecast (i.e. $31 \mathrm{~km}$ in 2012) and represents the uncertainties in the initial condition and the physical parameterisations. Exploring the ensemble members on stamp maps and spaghetti maps, the students concluded that the forecast of the severe weather over southern France was linked to the forecast of the interaction between Nadine and the cutoff low (Pantillon et al., 2015). They performed manual and automatic clustering of the ensemble forecast to understand the different scenarios. For automatic clustering a principal component analysis was used retaining the first two principal components. Figure $3 \mathrm{a}$ and $\mathrm{b}$ show a representative member of the two main clusters for the potential vorticity at $320 \mathrm{~K}$ and the geopotential at $500 \mathrm{hPa}$. Visualising probability and percentile maps brought the engineers closer to estimating the likelihood of extreme precipitation over southern France. Finally, with all the available forecast information, they gave advice to the "scientific director" to make a pre-alert decision on aircraft deployment. There was a discussion on the use 
(a) Member 2

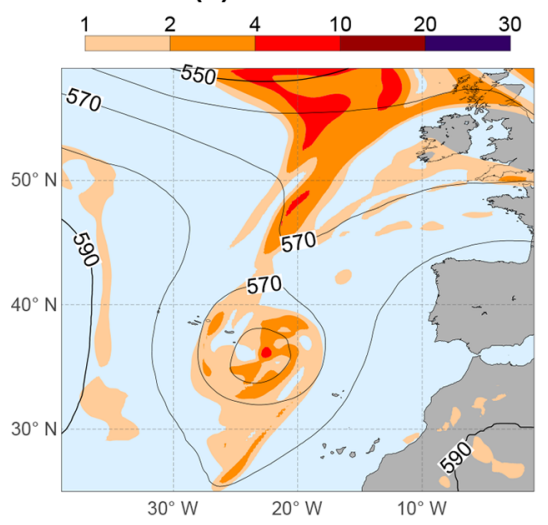

(d) HRES

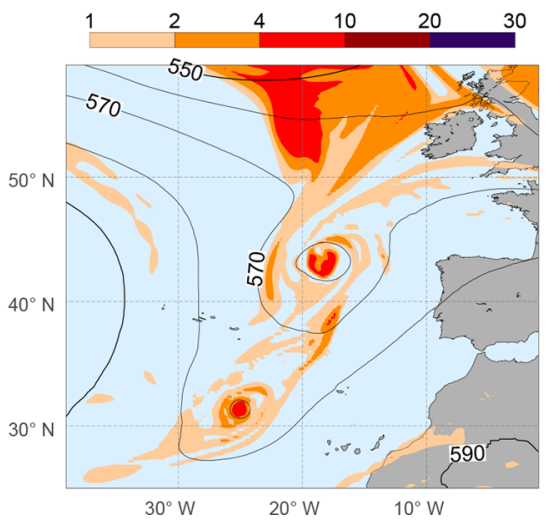

(b) Member 21

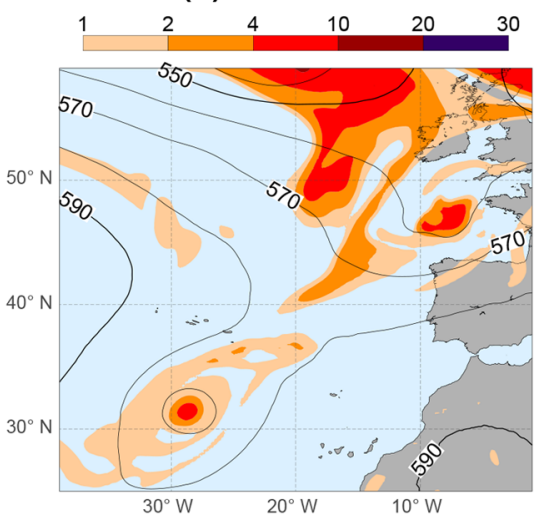

(e) Analysis

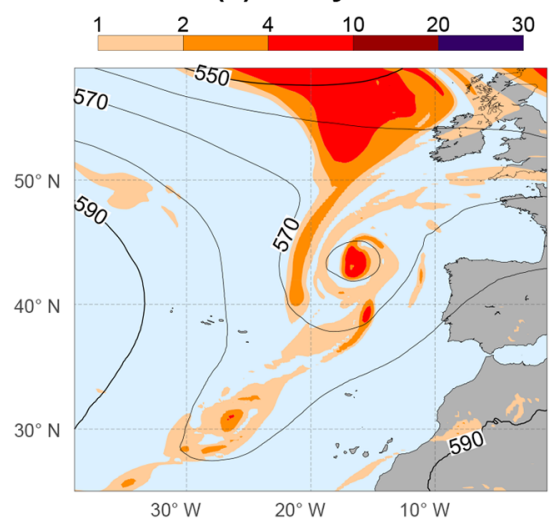

(c) Control

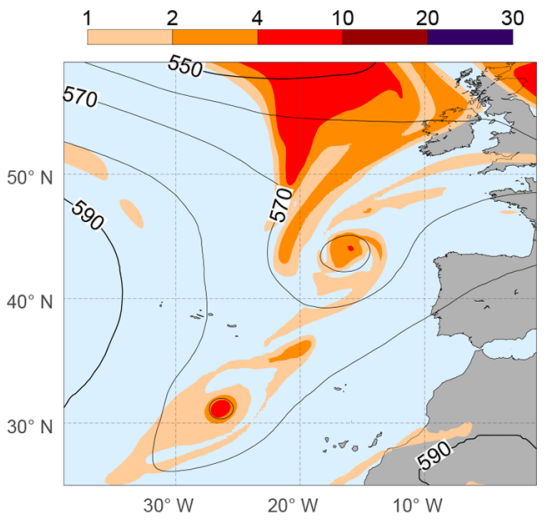

Figure 3. Potential vorticity at $320 \mathrm{~K}$ (pvu) and geopotential at $500 \mathrm{hPa}$ (dam) at 12:00 UTC on 22 September 2012 according to (a-b) two members of the operational ensemble forecast, (c) the control forecast, (d) the high-resolution forecast, each of them started at 00:00 UTC on 20 September 2012 (i.e. all are $60 \mathrm{~h}$ forecasts) and (e) the operational analysis. The ensemble members split to two substantially different scenarios for the interaction between Nadine and the Atlantic cut-off. Member 2 represents a scenario where Nadine and the cut-off rotate around each other tending to merge, while member 21 shows that Nadine moves westwards back to the ocean and the cut-off shifts eastwards. The HRES forecast indicated both Nadine and the cut-off being steered eastward. The control forecast predicted weak interaction and divergence between the two systems which was confirmed also by the analysis.

of cost/loss ratios to turn probability of a precipitation event into an eventual decision. The students were confronted with the actual forecast performance and ECMWF analyses of the event only on the last day when they calculated some error statistics.

Linux virtual machines have been employed in the courses at ENM since the beginning in 2016. Apart from the virtual machine player, there is no need to install software and files on the host computer. At the same time, some drawbacks have been identified from experience. The VM can be compressed to a single file, but as a full operating system with data and files, its size typically exceeds $10 \mathrm{~GB}$. It can freeze on computers with limited RAM when using software that is compute and memory intensive (e.g. Metview). Exporting the output files via USB, shared folders or network transfer (for presentation by the tutor to the class for example) can be problematic relying on kernel changes to the VM that do not always work. In 2018 a few virtual machines were hosted on the Copernicus Climate Data Store (CDS). The CDS is a cloud-based system to browse and combine raw data, access information about the past, present and future climate, develop and build own applications, maps and graphs online using a set of available software (Raoult et al., 2017). The virtual machines were prepared as VM "instances" on the CDS cloud server and provided to some of the students who reached them through a web browser after logging into the CDS, whilst the others used the VM installed on the classroom PCs. The system provided more stability and relied less on local computing capacity. Nevertheless, some new issues were encountered: the responsiveness of the CDS VMs could not match the local VMs; Metview animations and Metview scripts required noticeably longer times to complete despite generous resource allocation on the CDS. Although the internal cloud network eased moving the images between the 
CDS VMs for class presentation, copying the results to the local accounts can be still complicated if the local (firewall etc.) settings do not support that. Considering that cloud services rely on network and cloud resource allocation, they may work best for less compute intensive or slower paced workshops.

\section{NumLab at the University of Helsinki}

The Laboratory course in numerical modelling, commonly referred to as NumLab, is taught at the University of Helsinki, Finland every year as part of the 2-year masters program in atmospheric sciences. NumLab is designed to give students completing their masters degrees relevant work-life skills. Its specific learning objectives are:

1. to develop basic skills in high-performance computing relevant for meteorology;

2. to acquire practical, hands-on experience of using a state-of-the-art, complex atmospheric forecast model;

3. to learn to develop research questions, design relevant numerical experiments and apply meteorological knowledge from earlier courses and scientific reasoning to address research questions and

4. to develop transferable skills in scientific problem solving as a research group member and in presenting scientific results in a conference style presentation.

Historically, a different numerical model was selected each time NumLab was taught. However, this resulted in a large amount of preparation each year and often the lecturers had to first learn the model themselves. Since 2015, OpenIFS has been used as the numerical model in NumLab and will continue to be so for the foreseeable future. OpenIFS was selected for numerous reasons: it is based on a state-of-the-art operational model, IFS; research in the dynamic meteorology group at the University of Helsinki relies now largely on OpenIFS; climate research at the University of Helsinki is based on EC-Earth (Hazeleger et al., 2010) which has a version of IFS as its atmospheric component; operational shortterm forecasts at the Finnish Meteorological Institute are based on the HARMONIE model (HIRLAM-ALADIN Research for Mesoscale Operational NWP In Europe; Bengtsson et al., 2017) which has a dynamical core similar to IFS.

The NumLab course is worth 5 credit points in the European Credit Transfer and Accumulation System (ECTS; one year of full study is worth 60 credit points). It runs over two distinct 7 -week teaching periods with a $2 \mathrm{~h}$ contact session per week. In the first 7 weeks, short lectures are given during the contact sessions on topics such as useful Linux commands, architecture of a supercomputer, an overview of IFS incorporating information about the space-time discretisation, the state variables, parametrised physical processes (etc.), and the output file formats from OpenIFS (gridpoint versus spectral coefficients). The students work individually and learn how to compile and run the model, post-process and analyse the model outputs and improve their basic Linux and high-performance computing skills and knowledge (for example, using batch queue systems).

During the second part of the course the participants work in groups of 3-4 students on a small research project. Each year, a different scientific topic or specific historical weather event is selected as the basis of the course. Previous topics have included the extra-tropical wind storm Lothar, the parameterisation of deep convection and forecast skill drop outs over Europe which was studied using ensemble simulations. The students design their own research questions and numerical experiments, with input and guidance from lecturers, and then conduct and analyse the simulations. One example of a research project undertaken by a group of students who studied the Lothar storm was to alter the surface roughness over land and investigate what impact this had on the forecast $10 \mathrm{~m}$ wind gusts. In the year when the focus was on deep convection another group explored the impact of entrainment on the amount of cloudiness and convective precipitation over central Africa.

The topic in 2019 is the sudden stratospheric warming of February 2018 which resulted in cold conditions over large parts of Europe. As the theme changes each year, it is possible for students to take the course more than once and the course can also be included in doctoral studies. To date more than 50 students have participated in the course and have learnt how to use OpenIFS. Most of them stated in their feedbacks that they learnt new skills and enjoyed having the opportunity to apply knowledge gained from earlier courses. Some students have commented that there is a very steep learning curve at the start of the course. In the future it is likely that the course will be opened up to remote participation.

\section{Teaching numerical modelling at Eötvös Loránd University in Budapest}

A two-semester course is dedicated to numerical weather prediction (NWP) and climate modelling at Eötvös Loránd University in Budapest, Hungary. In the first term, the masters students of Meteorological Department learn about theoretical basics of meteorological modelling: discretisation methods, finite difference technique, Galerkin methods, numerical stability, data assimilation, ensemble predictions etc. The lectures are given by modelling practitioners of the Hungarian Meteorological Service. The proceeding semester allows the attendees to try in practice what they learnt in the theory course. Further master students join from Department of Applied Analysis and Computational Mathematics and they form small teams with the meteorology students. The teams comprise of 2 to 4 members working on differ- 
(a) T255L91 OpenIFS; $t+27$

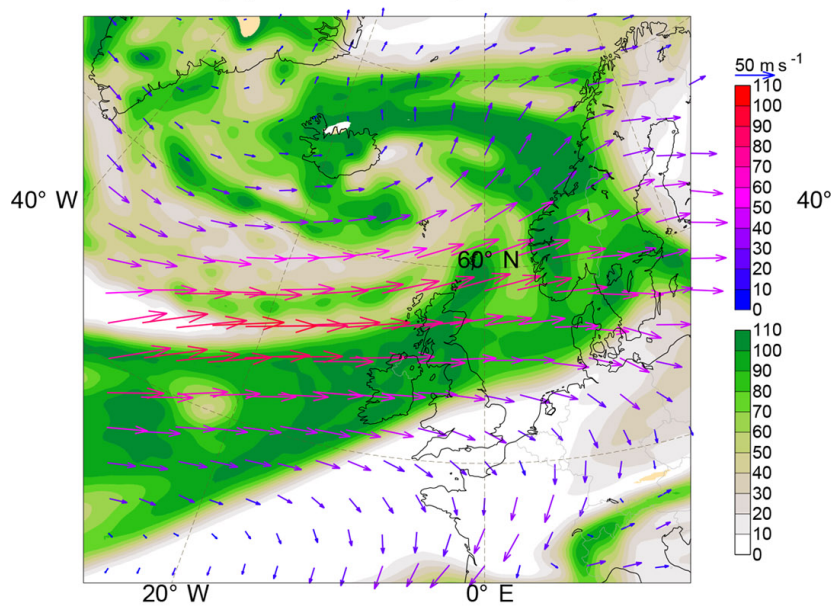

(c) ERA5 (b) T639L137 OpenIFS; t+27

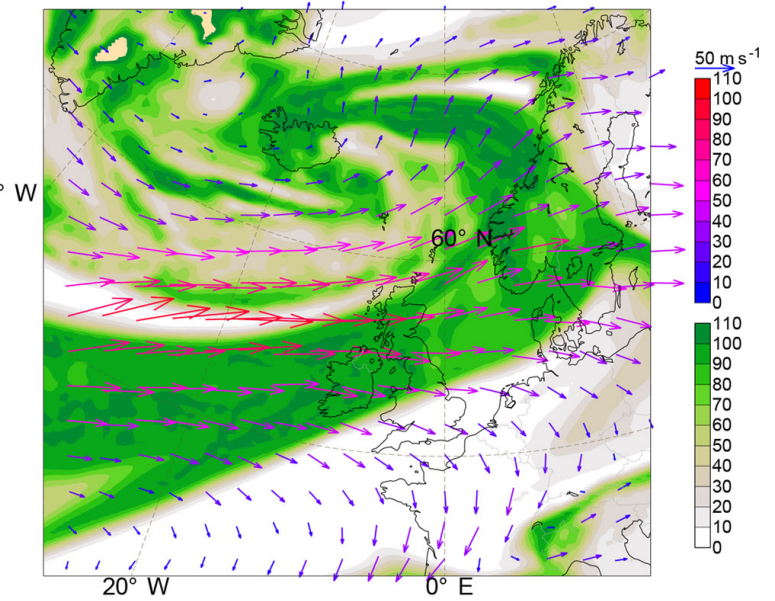

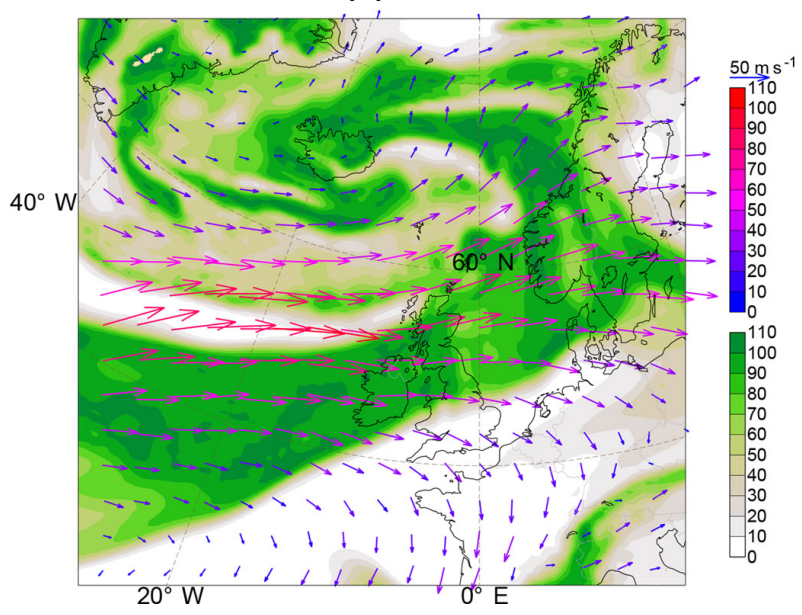

Figure 4. Relative humidity at $700 \mathrm{hPa}\left(\%\right.$; in brown and green) and wind speed at $250 \mathrm{hPa}\left(\mathrm{m} \mathrm{s}^{-1}\right.$; with arrows) at 03:00 UTC on $5 \mathrm{De}-$ cember 2015 according to (a) the T255L91 and (b) T639L137 resolution OpenIFS forecasts initialised from ERA-Interim at 00:00 UTC on 4 December 2015 and (c) the ERA5 reanalysis. The south-southwestern stream transported moisture from the tropics to north western Europe through the Atlantic Ocean in a narrow corridor. The wind speed in the upper-level jet stream exceeded $90 \mathrm{~m} \mathrm{~s}^{-1}$ in some grid points in the T639 resolution OpenIFS forecast as well as in ERA5.

ent modelling topics processing the related scientific articles and conducting simulations with numerical models available for educational purposes like the Lorenz models (Lorenz and Emanuel, 1998; Lorenz, 2005) and OpenIFS model. The students spend either an intensive week focusing solely on their project or a few hours every week during the semester consulting regularly with their supervisor from the meteorological institute. The programme closes with the teams' presentations in which they introduce the background of their chosen topic, their achieved experiments and discuss the conclusions drawn based on their results. The course strengthens the students' capabilities to work in teams. Especially beneficial is teams composed from students with a more theoretical background and those from the area of applications because that mimics the real work style in most meteorological services.
An evaluation framework was developed at ECMWF for OpenIFS version 40r1v2 in 2018 with the aim to provide a user tool for checking the meteorological performance of the model, comparing its different versions and testing the user developments. The tool is based on two weather events with severe impacts in Europe: storm Xaver from 2013 and storm Desmond from 2015. Several runs were conducted for both cases to study the effect of forecast length, initial conditions and spatial resolution on forecast quality. The experiments were initialised from the ERA-Interim and ERA5 reanalyses 1 to 5 days before the high-impact events using 3 different resolutions. The input data, the Metview-based visualisation programs, a detailed guidance about post-processing and plotting the model outputs, as well as the output figures are published online (Szépszó, 2008; Szépszó and Carver, 2018a, b). 
In 2018, a group of applied mathematics students from Eötvös Loránd University worked with OpenIFS. The Hungarian students tested the evaluation tool before its release. They reconstructed the experiments for Desmond at T255L91 and T639L137 resolution, initialised from ERAInterim on 4 December 2015, using OpenIFS 40r1 on the supercomputer of the Hungarian Meteorological Service. (The resolution of OpenIFS is specified by the spectral truncation prefixed by $\mathrm{T}$ for triangular truncation and associated with a linear Gaussian grid for the grid-point space computations, i.e. T255L91 and T639L137 correspond to 78 and $31 \mathrm{~km}$ grid spacing with 91 and 137 vertical levels, respectively.) The students visualised and evaluated the results following the guidance description step-by-step (Fig. 4). They compared the forecasts with ERA5 data (Hersbach et al., 2018) for different meteorological variables. The precipitation field was analysed with more detail, because not only OpenIFS, but also the ERA5 forecasts underestimated the rainfall with respect to the observational data. The students' feedbacks were taken into account at the final release of the evaluation package.

\section{Summary and outlook}

The courses based on the OpenIFS model help the masters and $\mathrm{PhD}$ students in developing and improving the knowledge and skills typically requested in scientific job announcements. Their analytical and problem solving skills are improved by the scientific mini-projects mapping the related literature and raising scientific questions based on the existing knowledge of the students. Their programming and scripting skills are enhanced by using a state-of-the-art numerical weather prediction model, analysing large datasets and handling model data in various formats. The courses give opportunities to work in a (sometimes multi-disciplinary) team as well as to discuss questions in English which both are highly desirable in meteorology where numerous developments are achieved in international collaborations.

The next OpenIFS model release in 2019 will make it possible to extend the research and teaching activities based on the model. OpenIFS version 43r3 will introduce the octahedral cubic grid used in ECMWF operational forecasts since 2015 which had significant benefits in terms of computational efficiency and representation of the resolved processes (Malardel et al., 2016). An offline version of the new radiation scheme ecRad (Hogan and Bozzo, 2016) has already been available for non-commercial use under the terms of the OpenIFS licence since 2017 and it will be included in the new OpenIFS version. It is faster than the radiation scheme of OpenIFS 40r1 (Morcrette et al., 2008) and its more flexible modular structure facilitates radiative transfer research. An interactive lake model (Balsamo and Belward, 2017) will be also available in the new version, based on the FLake parametrisation developed at the German Weather Service
(Mironov, 2008). A range of academic test cases such as the aquaplanet configuration (Neale and Hoskins, 2000a, b), the Held-Suarez case (Held and Suarez, 1994) is available in the current OpenIFS version to support teaching the dynamical meteorology. They will be extended with further pre-defined settings like for example baroclinic waves, idealised tropical cyclones in OpenIFS 43r3.

Data availability. Use of the OpenIFS model requires a free OpenIFS license from ECMWF which can be requested by email to openifs-support@ecmwf.int. The content of the virtual machines as well as the VM itself used in the OpenIFS workshops and the trainings introduced in Section 3 are available on request by email to openifs-support@ecmwf.int. The data and the programs mentioned in Section 5 can be retrieved from the ECMWF download server: http://download.ecmwf.int/test-data/openifs/reference_ casestudies (Szépszó and Carver, 2018b). The content is covered by the Creative Commons Attribution-Non-Commercial-NoDerivatives-4.0-Unported License, as described on https://www. ecmwf.int/en/terms-use (ECMWF, 2019). The tutorial for the exercises of Section 5 is available here: https://confluence.ecmwf.int/ x/jxwXBQ (Szépszó, 2018).

Author contributions. GS wrote the manuscript with input from all authors. GC designed the scientific and technical content of the OpenIFS workshops and the training introduced in Sect. 3. VS provided Sect. 4 and performed the work shown there. GS developed the OpenIFS evaluation package (with support of GC), carried out the work detailed in Sect. 5 and was involved in delivering some workshops discussed in the paper. The figures were made by GS. All authors contributed to the final version of the manuscript.

Competing interests. The authors declare that they have no conflict of interest.

Special issue statement. This article is part of the special issue "18th EMS Annual Meeting: European Conference for Applied Meteorology and Climatology 2018". It is a result of the EMS Annual Meeting: European Conference for Applied Meteorology and Climatology 2018, Budapest, Hungary, 3-7 September 2018.

Acknowledgements. The authors wish to thank the reviewers for their useful comments and suggestions improving the manuscript. Victoria Sinclair was funded by the Academy of Finland (project no. 307331) and wishes to acknowledge CSC - IT Center for Science, Finland, for computational resources used by the NumLab course.

Review statement. This paper was edited by Tomas Halenka and reviewed by Robert S. Plant and one anonymous referee 


\section{References}

Balsamo, G. and Belward, A.: Lakes in weather prediction: a moving target, ECMWF Newsletter, 150, p. 6, available at: https://www.ecmwf.int/en/newsletter/150/ news/lakes-weather-prediction-moving-target (last access: 2 April 2019), 2017.

Balsamo, G., Viterbo, P., Beljaars, A., van den Hurk, B., Hirschi, M., Betts, A. K., and Scipal, K.: A revised hydrology for the ECMWF model: Verification from Field Site to Terrestrial Water Storage and Impact in the Integrated Forecast System, J. Hydrometeorol., 10, 623-643, https://doi.org/10.1175/2008JHM1068.1, 2009.

Bauer, P. and Richardson, D., New model cycle 40r1, ECMWF Newsletter, 138, p. 3, available at: https://www.ecmwf.int/en/ elibrary/14581-newsletter-no-138-winter-2013-14 (last access: 2 April 2019), 2014.

Bengtsson, L., Andrae, U., Aspelien, T., Batrak, Y., Calvo, J., de Rooy, W., Gleeson, E. Hansen-Sass, B., Homleid, M., Hortal, M., Ivarsson, K., Lenderink, G., Niemelä, S., Nielsen, K. P., Onvlee, J., Rontu, L., Samuelsson, P., Muñoz, D. S., Subias, A., Tijm, S., Toll, V., Yang, X., and Køltzow, M.Ø.: The HARMONIE-AROME Model Configuration in the ALADINHIRLAM NWP System, Mon. Weather Rev., 145, 1919-1935, https://doi.org/10.1175/MWR-D-16-0417.1, 2017.

Buizza, R., Miller, M., and Palmer, T. N.: Stochastic representation of model uncertainties in the ECMWF Ensemble Prediction System, Q. J. Roy. Meteor. Soc., 125, 2887-2908, https://doi.org/10.1002/qj.49712556006, 1999.

Carver, G.: OpenIFS users explore atmospheric predictability, ECMWF Newsletter, 153, 6-7, available at: https://www.ecmwf.int/en/newsletter/153/news/ openifs-users-explore-atmospheric-predictability (last access: 2 April 2019), 2017.

Carver, G., Váňa, F., Kertész, S., Källén, E., Sinclair, V., and Järvinen, H.: University of Helsinki meeting on OpenIFS, ECMWF Newsletter, 136, p. 4, available at: http://www.ecmwf.int/sites/default/files/elibrary/2013/ 14593-newsletter-no136-summer-2013.pdf (last access: 2 April 2019), 2013.

Carver, G., Kertész, S., Váňa, F., Ferry, F., and Chabot, E.: MétéoFrance hosts OpenIFS workshop, ECMWF Newsletter, 149, $2-$ 3, available at: https://www.ecmwf.int/sites/default/files/elibrary/ 2016/16759-newsletter-no149-autumn-2016.pdf (last access: 2 April 2019), 2016.

Drobinski, P., Ducrocq, V., Alpert, P., Anagnostou, E., Béranger, K., Borga, M., Braud, I., Chanzy, A., Davolio, S., Delrieu, G., Estournel, C., Boubrahmi, N. F., Font, J., Grubišić, V., Gualdi, S., Homar, V., Ivančan-Picek, B., Kottmeier, C., Kotroni, V., Lagouvardos, K., Lionello, P., Llasat, M. C., Ludwig, W., Lutoff, C., Mariotti, A., Richard, E., Romero, R., Rotunno, R., Roussot, O., Ruin, I., Somot, S., Taupier-Letage, I., Tintore, J., Uijlenhoet, R., and Wernli, H.: HyMeX: A 10-Year Multidisciplinary Program on the Mediterranean Water Cycle, B. Am. Meteorol. Soc., 95, 1063-1082, https://doi.org/10.1175/BAMS-D-1200242.1, 2014.

ECMWF: Terms of use, available at: https://www.ecmwf.int/en/ terms-use, last access: 2 April 2019.
Fraedrich, K. and Müller, K.: Climate anomalies in Europe associated with ENSO extremes, Int. J. Climatol., 12, 25-31, https://doi.org/10.1002/joc.3370120104, 1992.

Hannachi, A. and Carver, G.: Second OpenIFS user meeting at Stockholm University, ECMWF Newsletter, 140, 23, available at: https://www.ecmwf.int/sites/default/files/elibrary/ 2014/14583-newsletter-no140-summer-2014.pdf (last access: 2 April 2019), 2014.

Hazeleger, W., Severijns, C., Semmler, T., Ştefănescu, S., Yang, S., Wang, X., Wyser, K., Dutra, E., Baldasano, J. M., Bintanja, R., Bougeault, P., Caballero, R., Ekman, A. M., Christensen, J. H., van den Hurk, B., Jimenez, P., Jones, C., Kållberg, P., Koenigk, T., McGrath, R., Miranda, P., van Noije, T., Palmer, T., Parodi, J. A., Schmith, T., Selten, F., Storelvmo, T., Sterl, A., Tapamo, H., Vancoppenolle, M., Viterbo, P., and Willén, U.: EC-Earth: A Seamless Earth-System Prediction Approach in Action, B. Am. Meteorol. Soc., 91, 1357-1364, https://doi.org/10.1175/2010BAMS2877.1, 2010.

Held, I. and Suarez, M.: A proposal for the intercomparison of the dynamical cores of atmospheric general circulation models, B. Am. Meteorol. Soc., 73, 1825-1830, https://doi.org/10.1175/15200477(1994)075<1825:APFTIO>2.0.CO;2, 1994.

Hersbach, H., de Rosnay, P., Bell, B., Schepers, D., Simmons, A., Soci, C., Abdalla, S., Alonso-Balmaseda, A., Balsamo, G., Bechtold, P., Berrisford, P., Bidlot, J.-R., de Boisséson, E., Bonavita, M., Browne, P., Buizza, R., Dahlgren, P., Dee, D., Dragani, R., Diamantakis, M., Flemming, J., Forbes, R., Geer, A., Haiden, T., Hólm, E., Haimberger, L., Hogan, R., Horányi, A., Janisková, M., Laloyaux, P., Lopez, P., MuñozSabater, J., Peubey, C., Radu, R., Richardson, D., Thépaut, J-N., Vitart, F., Yang, X., Zsótér, E., and Zuo, H.: Operational global reanalysis: progress, future directions and synergies with NWP, ECMWF ERA Report Series, 27, available at: https://www.ecmwf.int/sites/default/files/elibrary/2018/18765operational-global-reanalysis-progress-future-directions-andsynergies-nwp.pdf (last access: 2 April 2019), 2018.

Hogan, R. J. and Bozzo, A.: ECRAD: a new radiation scheme for the IFS, ECMWF Technical Memorandum, 787, available at: https://www.ecmwf.int/sites/default/files/elibrary/ 2016/16901-ecrad-new-radiation-scheme-ifs.pdf (last access: 2 April 2019), 2016.

Leutbecher, M., Lock, S.-J., Ollinaho, P., Lang, S. T. K., Balsamo, G., Bechtold, P., Bonavita, M., Christensen, H. M., Diamantakis, M., Dutra, E., English, S., Fisher, M., Forbes, R. M., Goddard, J., Haiden, T., Hogan, R. J., Juricke, S., Lawrence, H., MacLeod, D., Magnusson, L., Malardel, S., Massart, S., Sandu, I., Smolarkiewicz, P. K., Subramanian, A., Vitart, F., Wedi, N., and Weisheimer, A.: Stochastic representations of model uncertainties at ECMWF: state of the art and future vision, Q. J. Roy. Meteor. Soc., 143, 2315-2339, https://doi.org/10.1002/qj.3094, 2017.

Lorenz, E. N.: Designing Chaotic Models, J. Atmos. Sci., 62, 15741587, https://doi.org/10.1175/JAS3430.1, 2005.

Lorenz, E. N. and Emanuel, K. A.: Optimal Sites for Supplementary Weather Observations: Simulation with a Small Model, J. Atmos. Sci., 55, 399-414, https://doi.org/10.1175/15200469(1998)055<0399:OSFSWO>2.0.CO;2, 1998. 
Malardel, S., Wedi, N., Deconinck, W., Diamantakis, M., Kühnlein, C., Mozdzynski, G., Hamrud, M., and Smolarkiewicz, P.: A new grid for the IFS, ECMWF Newsletter, 146, 23-28, available at: https://www.ecmwf.int/sites/default/files/elibrary/2016/ 17262-new-grid-ifs.pdf (last access: 2 April 2019), 2016.

Mironov, D. V.: Parameterization of lakes in numerical weather prediction. Description of a lake model, COSMO Technical Report, 11, Deutscher Wetterdienst, Offenbach am Main, Germany, available at: http://www.cosmo-model.org/content/model/ documentation/techReports/docs/techReport11.pdf (last access: 2 April 2019), 2008.

Morcrette, J. J., Barker, H. W., Cole, J. N. S., Iacono, M. J., and Pincus, R.: Impact of a new radiation package, McRad, in the ECMWF integrated forecasting system, Mon. Weather Rev., 136, 4773-4798, https://doi.org/10.1175/2008MWR2363.1, 2008.

Neale, R. B. and Hoskins, B. J.: A standard test for AGCMs and their physical parameterizations I: The proposal, Atmos. Sci. Lett., 1, 101-107, https://doi.org/10.1006/asle.2000.0022, 2000a.

Neale, R. B. and Hoskins, B. J.: A standard test for AGCMs and their physical parameterizations II: Results for The Met. Office Model, Atmos. Sci. Lett., 1, 108-114, https://doi.org/10.1006/asle.2000.0024, 2000b.

Pantillon, F., Chaboureau, J.-P., and Richard, E.: Vortex-vortex interaction between Hurricane Nadine and an Atlantic cutoff dropping the predictability over the Mediterranean, Q. J. Roy. Meteor. Soc., 142, 419-432, https://doi.org/10.1002/qj.2635, 2015.

Plant, R. and Gray, S.: OpenIFS used by University of Reading students, ECMWF Newsletter, 152, 6-7, available at: https://www.ecmwf.int/en/newsletter/152/news/ openifs-used-university-reading-students (last access: 2 April 2019), 2017.
Raoult, B., Bergeron, C., Alós, A. L., Thépaut, J.-N., and Dee, D.: Climate service develops user-friendly data store, ECMWF Newsletter, 151, 22-27, available at: https://www.ecmwf.int/en/newsletter/151/meteorology/

climate-service-develops-user-friendly-data-store (last access: 2 April 2019), 2017.

Russell, I., Ii, F., Kertész, S., and Domínguez, J.-J.: Metview's 20th anniversary, ECMWF Newsletter, 138, p. 2, available at: http://www.ecmwf.int/sites/default/files/elibrary/2013/ 14581-newsletter-no138-winter-201314.pdf (last access: 2 April 2019), 2014.

Shutts, G. J.: A kinetic energy backscatter algorithm for use in ensemble prediction systems, Q. J. Roy. Meteor. Soc., 131, 30793102, https://doi.org/10.1256/qj.04.106, 2005.

Szépszó, G.: OpenIFS Meteorological Evaluation, available at: https://confluence.ecmwf.int/x/jxwXBQ (last access: 2 April 2019), 2018.

Szépszó, G. and Carver, G.: New forecast evaluation tool for OpenIFS, ECMWF Newsletter, 156, 14-15, available at: https://www.ecmwf.int/en/newsletter/156/news/ new-forecast-evaluation-tool-openifs (last access: 2 April 2019), 2018a.

Szépszó, G. and Carver, G.: OpenIFS reference case studies, available at: http://download.ecmwf.int/test-data/openifs/reference casestudies (last access: 2 April 2019), 2018b.

Váňa, F. and Ahlgrimm, M.: An introduction to single-column modelling, ECMWF eLearning online resources, available at: https:// www.ecmwf.int/assets/elearning/scm/story_html5.html (last access: 2 April 2019), 2018. 